http://jmscr.igmpublication.org/home/ ISSN (e)-2347-176x ISSN (p) 2455-0450

crossref DOI: https://dx.doi.org/10.18535/jmscr/v7i9.62

\author{
Journal Of Medical Science And Clinical Research \\ IGM Publication \\ An Official Publication of IGM Publication
}

\title{
A clinical study of etiology and management of Bell's palsy in a Tertiary Care Hospital
}

\author{
Authors \\ Yelma Bhooma Reddy ${ }^{1^{*}}, M_{\text {Hemanth Rao }}{ }^{2}$ \\ ${ }^{1}$ Department of ENT, Rajiv Gandhi Institute of Medical Sciences [RIMS], Adilabad, Telangana State, India \\ ${ }^{2}$ Assistant Professor, Department of ENT, Rajiv Gandhi Institute of Medical Sciences [RIMS], Adilabad, \\ Telangana State, India \\ *Corresponding Author \\ Dr Yelma Bhooma Reddy \\ Sri Laxmi Residency, Flat No 102, Opp Govt Girls high school, Vidyanagar, Adilabad-504001, India
}

\begin{abstract}
Bell's palsy is a common presentation in Otolaryngology practice. The aim of the present study to find the etiology and management of patients with Bell's palsy presenting to the Department of Otolaryngology in a tertiary care hospital. Methods: This prospective cross-sectional study was carried out in the Department of ENT, Rajiv Gandhi Institute of Medical Sciences [RIMS], Adilabad from September 2017 to Jan 2019. A total of $n=67$ patients $n=26$ male and $n=41$ females were included in the study. After complete history and clinical evaluation an initial dose of oral prednisolone 60mg/day in three divided doses for 7 days followed by tapering off within the next five days by 10mg/day reduction in a single-dose regimen. Advised serial follow up at the end of $1^{\text {st }}, 2^{\text {nd }}, 3^{\text {rd }}$ and $6^{\text {th }}$ week followed by 3 months and 6 months. Results: The grading of facial paresis was carried as per House-Brackmann scale most of the patients $n=33(49.25 \%)$ were detected with Grade II mild dysfunctions. Followed by moderate dysfunction grade III in $n=15(22.39 \%)$. Grades IV and V having $n=7(10.45 \%)$ each and grade VI in $n=5(7.46 \%)$. The majority patients were given steroids $n=36(53.73 \%)$ and steroids along with physiotherapy $n=15(22.39 \%)$, NSAID $n=21(31.34 \%)$, vitamin B12 $n=22(32.84 \%)$ and antiviral were for $n=10$ (14.92\%). Conclusion: The present study concludes that females are more commonly affected by Bell's palsy and the age group more affected is 30 - 40 years. Recurrence of Bell's palsy was also noted in some cases. Most of our patients responded to prednisolone and antiviral treatment, some were prescribed only steroids with physiotherapy. From our experience, we can assume that the treatment of Bell's palsy should be based on the etiology and needs of the patients and most of the cases will recover within acceptable limits.

Keywords: Bell's palsy, Etiology, Management, Tertiary care hospital.
\end{abstract}

\section{Introduction}

Bell's palsy is also known as acute idiopathic facial paralysis; it is an idiopathic neuropathy of the facial nerve. In some cases is considered to be acute immune demyelination of facial nerve triggered by some viral infection ${ }^{[1]}$. It is usually rapid in onset and usually, self-limiting and recovery is spontaneous within 6 months of onset, however, $20 \%$ of patients develop some type of sequelae, which may vary from a light degree of 
residual paralysis to complete unilateral or bilateral paralysis ${ }^{[2]}$. The annual incidence of facial palsy is reported between $15-30$ per 100,000 populations ${ }^{[3,4]}$. The incidence increases with age, familial inheritance is noted in $414 \%$ of the cases $^{[5]}$. The maximum incidence of Bell's palsy is between 15-45 years, usually affecting both sexes equally ${ }^{[6]}$. Pietersen found that both sides are affected equally some studies have shown left side predominance ${ }^{[7]}$. Studies have shown that no seasonal pattern exists, however, De Diego et al; have shown the incidence appears to more in winter season as compared to summer ${ }^{[8]}$. Jabor et al; have reported that $84 \%$ of patients with Bell's palsy recovered without any treatment and only $16 \%$ had residual paralysis. The prognosis depends on the degree of paresis, age of the patient, time lag between appearances of symptoms and reporting to the hospital ${ }^{[9]}$. The other important factors affecting the outcome of treatment include severe post-auricular pain, age older than 60 years, hypertension or diabetes mellitus, hyperacusia, decreased lacrimation, psychological stress, and severe facial pain predicts a poor outcome ${ }^{[10]}$. Treatment modalities for Bell's palsy are not clearly defined. It involves conservative approaches like physiotherapy which include facial exercises, muscle relaxation; medical treatments include cortisone, anti-viral agents, and Botox. Grogan et al; stated in the American Academy of Neurology practice that for patients with Bell's palsy a definitive benefit can be derived from treatment with steroids, acyclovir, facial nerve decompression ${ }^{[11]}$. Some pieces of evidence have suggested that steroids with acyclovir are most effective in improving facial nerve functions. With this background, we in the present study tried to evaluate the etiology of Bell's palsy and treatment in this tertiary care and teaching hospital located in Adilabad District which caters the needs of the predominantly tribal people.

\section{Material and Methods}

This prospective cross-sectional study was carried out in the Department of ENT, Rajiv Gandhi Institute of Medical Sciences [RIMS], Adilabad a tertiary care hospital from September 2017 to January 2019. Institutional Ethical committee permission was obtained for the study. Written consent was obtained from all the participants of the study. The inclusion criteria were patients above the age of 15 years with acute unilateral lower motor neuron facial paralysis. Exclusion criteria were patients with a history of recent middle ear infection, malignancy, infections, HIV positive autoimmune disorders, and severe head injuries. Based on the inclusion and exclusion criteria a total of $n=70$ patients were initially selected out of which $n=27$ males and $n=43$ females. However, in the follow up $n=1$ male and $\mathrm{n}=2$ females did not report hence finally $\mathrm{n}=26$ male and $n=41$ females were finally included in the study. The complete history was obtained from the patients, the severity of facial weakness assessed clinically, duration between onset and presentation to the hospital was recorded, and pain at the mastoid, vertigo or dizziness, hypertension and diabetes mellitus and history of recurrence was recorded. Hearing defects were assessed and blood samples were obtained for complete blood count, BUN, creatinine, FBS, electrolytes, ESR were recorded. CXR was done to exclude pulmonary infections or neoplasms. A CT scan of the brain was performed to exclude intracranial abnormality. After complete evaluation an initial dose of oral prednisolone $60 \mathrm{mg} /$ day in three divided doses for 7 days followed by tapering off within the next five days by $10 \mathrm{mg} /$ day reduction in a single-dose regimen. Some of the patients were also prescribed NSAID's and vitamins; antiviral was used in one person suffering from Ramsay-Hunt Syndrome. All of the patients were advised serial follow up at the end of $1^{\text {st }}, 2^{\text {nd }}, 3^{\text {rd }}$ and $6^{\text {th }}$ week followed by 3 months and 6 months. 


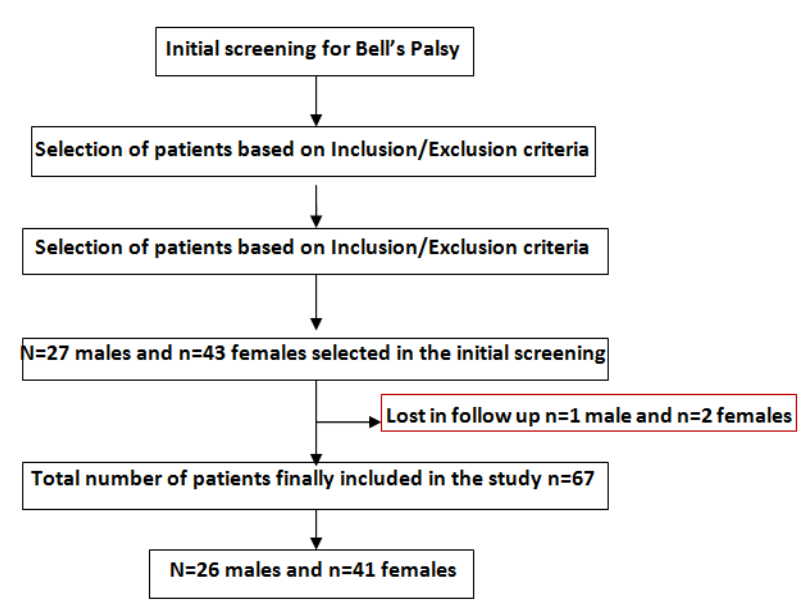

\section{Results}

During the period of the study, a total of $n=67$ patients were seen out of which $n=26$ were male and $n=41$ were females. The male to female ratio in this study was 1: 1.5. The most common age group involved was 31- 40 years with $\mathrm{n}=26(38.8 \%)$ of patients followed by age group 41 - 50 years $n=12(17.91 \%)$ of patients. The other age-wise and sex-wise distributions of patients in different age groups are shown in table 1.

Table 1: showing the distribution of Bell's palsy in the study

\begin{tabular}{|l|c|c|c|c|}
\hline Age Group & Male & Female & Total & Percentage \\
\hline $\mathbf{1 5}-\mathbf{2 0}$ & 01 & 03 & 04 & 5.97 \\
\hline $\mathbf{2 1}-\mathbf{3 0}$ & 03 & 06 & 09 & 13.44 \\
\hline $\mathbf{3 1}-\mathbf{4 0}$ & 11 & 15 & 26 & 38.80 \\
\hline $\mathbf{4 1 - 5 0}$ & 07 & 05 & 12 & 17.91 \\
\hline $\mathbf{5 1}-\mathbf{6 0}$ & 02 & 06 & 08 & 11.94 \\
\hline $\mathbf{6 1 - 7 0}$ & 01 & 04 & 05 & 7.46 \\
\hline$>\mathbf{7 0}$ & 01 & 02 & 03 & 4.47 \\
\hline Total & 26 & 41 & 67 & 100 \\
\hline
\end{tabular}

The predominant side involved in Bell's palsy in this group of patients was left side with $n=38$ $(56.23 \%)$ of patients and the right side was involved in $\mathrm{n}=29$ (43.28\%). The first-time occurrence was seen in the majority of patients $\mathrm{n}=55(82.09 \%)$ and recurrent Bell's palsy was seen in $\mathrm{n}=12(17.91 \%)$ of patients the sex-wise distribution of the same is given in table 2 .
Table 2: Showing the side involved for Bell's palsy and occurrence

\begin{tabular}{|l|c|c|c|c|}
\hline & Male & Female & Total & percentage \\
\hline Side & 14 & 24 & 38 & 56.72 \\
\hline Left & 12 & 17 & 29 & 43.28 \\
\hline Right & 26 & 41 & 67 & 100 \\
\hline Total & \multicolumn{5}{|l|}{} \\
\hline Occurrence \\
\hline First time & 21 & 34 & 55 & 82.09 \\
\hline Recurrent & 05 & 07 & 12 & 17.91 \\
\hline Total & 26 & 41 & 67 & 100 \\
\hline
\end{tabular}

The grading of facial paresis was carried as per the House-Brackmann scale to determine the degree of facial dysfunction in the study ${ }^{[12]}$. Most of the patients $n=33(49.25 \%)$ were detected with Grade II mild dysfunctions. Followed by moderate dysfunction grade III in $\mathrm{n}=15(22.39 \%)$. Grades IV and $\mathrm{V}$ having $\mathrm{n}=7(10.45 \%)$ each and grade VI in $\mathrm{n}=5 \quad(7.46 \%)$ of patients the gender-wise distribution is given in table 3 .

The symptoms recorded in the patients during the study showed that pain over mastoid was present in $\mathrm{n}=31(46.26 \%)$ of patients followed by preceding viral infection in $\mathrm{n}=12(29.85 \%)$ of patients, vertigo dizziness in $\mathrm{n}=12(17.91 \%)$, decreased lacrimation in $\mathrm{n}=7(14.45 \%)$, Headache in $\mathrm{n}=6(8.95 \%)$, and hearing defect in $\mathrm{n}=5(7.46 \%)$ of patients. The most common etiology was idiopathic in $\mathrm{n}=58(86.57 \%)$ cases, stroke $\mathrm{n}=6(8.96 \%)$, traumatic etiology in $\mathrm{n}=2(2.98 \%)$, $\mathrm{n}=1(1.49 \%)$. The symptoms and etiology in this group of patients sex-wise are given in table 4 .

Table 3: Grading of facial paresis at initial presentation as per the House-Brackmann scale [12]

\begin{tabular}{|l|c|c|c|c|}
\hline $\begin{array}{l}\text { House-Brackmann } \\
\text { scale for grading of } \\
\text { facial paresis }\end{array}$ & Male & Female & Total & $\begin{array}{c}\text { Percen } \\
\text { tage }\end{array}$ \\
\hline Grades & & & & \\
\hline I. Normal & 00 & 00 & 00 & 00.00 \\
\hline II. Mild dysfunction & 12 & 21 & 33 & 49.25 \\
\hline $\begin{array}{l}\text { III. Moderate } \\
\text { dysfunction }\end{array}$ & 05 & 10 & 15 & 22.39 \\
\hline $\begin{array}{l}\text { IV. Moderately severe } \\
\text { dysfunction }\end{array}$ & 03 & 04 & 07 & 10.45 \\
\hline V.Severe dysfunction & 04 & 03 & 07 & 10.45 \\
\hline VI. Total paralysis & 02 & 03 & 05 & 7.46 \\
\hline
\end{tabular}


Table 4: The symptoms of patients in the study

\begin{tabular}{|c|c|c|c|c|}
\hline & Male & Female & Total & Percentage \\
\hline \multicolumn{5}{|l|}{ Symptoms } \\
\hline Pain at mastoid & 21 & 10 & 31 & 46.26 \\
\hline $\begin{array}{l}\text { Vertigo } \\
\text { dizziness }\end{array}$ & 04 & 08 & 12 & 17.91 \\
\hline $\begin{array}{l}\text { Preceding viral } \\
\text { infection }\end{array}$ & 12 & 08 & 20 & 29.85 \\
\hline Hearing defect & 01 & 00 & 05 & 7.46 \\
\hline $\begin{array}{l}\text { Decreased } \\
\text { lacrimation }\end{array}$ & 04 & 03 & 07 & 14.45 \\
\hline Headache & 03 & 03 & 06 & 8.95 \\
\hline
\end{tabular}

The presence of co-morbidities was noted in the study with $\mathrm{n}=25(37.31 \%)$ patients having hypertension and $\mathrm{n}=10(14.92 \%)$ and $\mathrm{n}=10(14.92 \%)$ were having diabetes mellitus shown in table 4.

Table 5: Showing the presence of co-morbidities in the patients of the study

\begin{tabular}{|l|c|c|c|c|}
\hline $\begin{array}{l}\text { Co- } \\
\text { Morbidities }\end{array}$ & Male & Female & Total & percentage \\
\hline \multicolumn{5}{|c|}{ Hypertension } \\
\hline Yes & 15 & 10 & 25 & 37.31 \\
\hline No & 11 & 31 & 42 & 62.68 \\
\hline Total & 26 & 41 & 67 & 100 \\
\hline \multicolumn{5}{|c|}{ Diabetes Mellitus } \\
\hline Yes & 04 & 06 & 10 & 14.92 \\
\hline No & 22 & 35 & 57 & 85.07 \\
\hline Total & 26 & 41 & 67 & 100 \\
\hline
\end{tabular}

Majority of patients $n=60(89.55 \%)$ in the study reported to the hospital within 48 hours $n=7$ (10.44\%) reported within 48 to 72 hours. The majority patients were given steroids $\mathrm{n}=36(53.73 \%)$ and steroids along with physiotherapy $\mathrm{n}=15(22.39 \%)$, NSAID $\mathrm{n}=21(31.34 \%)$, vitamin B12 $\mathrm{n}=22(32.84 \%)$ and antiviral were for $\mathrm{n}=10(14.92 \%)$.

Table 6: showing the treatment given to the patients in the study

\begin{tabular}{|l|c|c|}
\hline Treatment & Total & Percentage \\
\hline Steriods & 36 & 53.73 \\
\hline Steriods + Physiotherapy & 15 & 22.39 \\
\hline $\begin{array}{l}\text { Anti-inflammatory } \\
\text { (NSAID) }\end{array}$ & 21 & 31.34 \\
\hline Antiviral & 10 & 14.92 \\
\hline Vitamin B12 & 22 & 32.84 \\
\hline
\end{tabular}

\section{Discussion}

The study showed that the mean age of onset of Bell's palsy was 43.5 years in male and 40.5 years in females. Stanley $\mathrm{M}$ et al; have shown that patients from age group $23-32$ were most commonly involved with facial palsy ${ }^{[13]}$. A similar study has shown that the middle age group 20 - 34 years had the highest incidence of facial palsy and older age group had the least incidence of facial palsy $^{[14]}$. The male to female ratio was $1: 1.5$ with the predominance of females in this study. Batista $\mathrm{KT}^{[15]}$ and Junior NA et al; ${ }^{[16]}$ have shown that facial palsy predominates in males. On the contrary study by Hohman $\mathrm{MH}$ et $a{ }^{[17]}$ have shown $81 \%$ of females involved with facial palsy agreeing with the results of the present study. The left side was involved in $\mathrm{n}=38(56.23 \%)$ of patients and right side in $n=29(43.28 \%)$ of cases of the present study. The difference in this study based on the side is only minor hence it does not show any side predilection. Other similar studies from different regions of the world also did not demonstrate any particular side affected in Bell's palsy $^{[7,8,18]}$. Assessment of acute facial paralysis is very important and physicians must find the specific cause in the individuals since the differential diagnosis may include critical conditions such as cerebrovascular accidents or malignancy which can lead to significant morbidity if they are untreated ${ }^{[19]}$. The HouseBrackmann scale for grading of facial paresis is accepted as a standard to describe the facial functions ${ }^{[12]}$. Assessing the functions in the patients helps the otolaryngologist to determine the prognosis and management of the patients. In the present study, the House-Brackmann scale was used to assess the function of the facial nerve at the initial presentation given in table 3 . In this study, we found most of the patients belonging to grade II with mild dysfunctions. Most of them recovered with treatment. 2 patients with grade VI did not recover hence they were referred for super-specialty care. The classical clinical manifestations of the Bell's palsy will be seen as the flattening of the forehead and nasolabial fold, 
eyebrow sagging, unable to close eyes, draw of the angle of the mouth to the non-affected side. Failure of eye closure can lead to corneal ulceration, scarring, and impairment of vision if not managed timely ${ }^{[20]}$. In this study, we found $\mathrm{n}=25(37.31 \%)$ patients with hypertension and $\mathrm{n}=10(14.92 \%)$ patients with diabetes. Several studies have discussed the role of diabetes and hypertension as a risk factor for Bell's palsy. Some studies have shown that hypertension along with increased age has an association with Bell's palsy ${ }^{[21-23]}$. There has been increasing attention for hypertension among children and pregnant women with Bell's palsy. ${ }^{[24-26]}$. Diabetes, in particular, is known to increase predisposition for Bell's palsy. Some investigators have noted that large randomized double-blind studies are needed to ascertain the effectiveness of glucocorticoids and antiviral agents ${ }^{[27]}$. In a review of Bell's palsy using antiviral agents, Alberton et $\mathrm{al}^{\left[{ }^{[28]}\right.}$ have stated that the use of acyclovir is controversial. Some authors are of the view that the combination of acyclovir and prednisone should be done if symptoms are less than 72 of onset. In the present study, we judiciously restricted the use of antiviral and corticosteroid combination when the patients were suspected the etiology of Bell's palsy to of viral origin. Most of the patients in our study have responded satisfactorily to treatment except 2 patients which required referral.

\section{Conclusion}

The present study concludes that females are more commonly affected by Bell's palsy and the age group more affected is 30 - 40 years. Recurrence of Bell's palsy was also noted in some cases. Most of our patients responded to prednisolone and antiviral treatment, some were prescribed only steroids with physiotherapy. From our experience, we can assume that the treatment of Bell's palsy should be based on the etiology and needs of the patients and most of the cases will recover within acceptable limits.
Conflict of Interest: None

Source of support: Nil

Ethical permission: Obtained

\section{References}

1. A Zandian, S Osiro, R Hudson, et al; The neurologist's dilemma: A comprehensive clinical review of Bell's palsy with emphasis on current management trends. Med Sci Monit 2014; 20:83-90.

2. Vlastou C. Facial paralysis. Microsurgery 2006; 26(4): 278-87.

3. Grogan PM, Gronseth GS. Practice parameter: Steroids, acyclovir, and surgery for Bell's palsy (an evidence-based review): Report of the quality standards subcommittee of the American academy of neurology. Neurology 2001; 56(7): 83036.

4. Ljøstad U, Økstad S, Topstad T, Mygland A, Monstad P. Acute peripheral facial palsy in adults. J Neurol 2005; 252(6): 672-76.

5. Döner F, Kutluhan S. Familial idiopathic facial palsy. Eur Arch Otorhinolaryngol 2000; 257(3): 117-19.

6. Rowlands S, Hooper R, Hughes R, Burney $P$. The epidemiology and treatment of Bell's palsy in the UK. Eur J Neurol 2002; 9(1): 63-67.

7. Peitersen E. Bell's palsy the spontaneous course 2,500 peripheral facial nerve palsies of different aetiologies. Acta Otolaryngol 2002; 549: 4-30.

8. De DJ Prim MP, Madero R, Marco S, Gavian J. Effect of atmospheric factors on the incidence of Bell's palsy. Eur Arch Otorhinolaryngol 2002; 259(1):53-55.

9. Jabor MA, Gianoli G. Management of Bell's palsy. J La State Med Soc 1996; 148(7):279-83.

10. Adour KK, Hilsinger RL Jr, Callan EJ. Facial paralysis and Bell's palsy: a protocol for differential diagnosis. Am J Otol 1985; (Suppl): 68-73. 
11. Grogan PM, Gronseth GS. Practice parameter: Steroids, acyclovir, and surgery for Bell's palsy (an evidence-based review): Report of the Quality Standards Subcommittee of the American Academy of Neurology. Neurology 2001; 56 (7):830-36.

12. House JW; Brackmann DE. Facial nerve grading system. Otolaryngol Head Neck Surg 1985; 93(2):146-47.

13. Stanley M, Ifeanyi UC, Zuwera S, Yunus OA, Theophilus D, Abiodun JO. Review of facial nerve palsy at a tertiary hospital in Maiduguri, Nigeria. American Journal of Health Research 2016; 4(4): 100-03.

14. Lamina S, Hanif S. Pattern of facial palsy in a typical Nigerian specialist hospital. African Health Sciences 2012; (4):514 17.

15. Batista KT. Facial paralysis: epidemiological analysis in a rehabilitation hospital. Rev. Bras. Cir. Plást. 2011; 26(4): 591-95.

16. Junior NA, Jorge Junior JJ, Gignon VF, Kitice AT, de Almeida Prado LS, Wolff Santos VG. Facial Nerve Palsy: Incidence of different etiologies in a tertiary ambulatory. Intl. Arch. Otorhinolaryngol., São Paulo 2009; 13(2):167-71.

17. Hohman MH, Hadlock TA. Etiology, diagnosis, and management of Facial palsy: 2000 patients at a facial nerve center. Laryngoscope 2014; 124: 283-293.

18. Katusic SK, Beard CM, Wiederholt WC, Bergstralh EJ, Kurland LT. Incidence, clinical features, and prognosis in Bell's palsy, Rochester, Minnesota, 1968-1982. Ann Neurol 1986; 20(5): 622-67.

19. Costa Apostolides, Michele M Carr. Assessment and management of idiopathic facial (Bell's) Palsy: comparison of Nova Scotia family physicians and otolaryngologists. The Journal of Otolaryngology 2000; 29(1): 17-22.
20. Lane C. Management of ocular surface exposure. Br J Ophthalmol 2012;96(4): 471-72.

21. Brandenburg NA, Annegers JF: Incidence and risk factors for Bell's palsy in Laredo, Texas: 1974-1982. Neuroepidemiology $1993 ; 12: 313-325$.

22. Accomando J, D’Agostino A, Adelman HM: An unusual manifestation of diabetes mellitus. Hosp Pract (Minneap) 1999; 34:39-40.

23. Paolino E, Granieri E, Tola MR, Panarelli MA, Carreras M: Predisposing factors in Bell's palsy: a case-control study. J Neurol 1985; 232:363-65.

24. Shmorgun D, Chan WS, Ray JG: Association between Bell's palsy in pregnancy and preeclampsia. Q J Med 2002; 95:359-62.

25. Loggie JM: Evaluation and management of childhood hypertension. Surg Clin North Am 1985; 65:1623-49.

26. Shapiro JL, Yudin MH, Ray JG: Bell's palsy and tinnitus during pregnancy: predictors of pre-eclampsia? Three cases and a detailed review of the literature. Acta Otolaryngol 1999; 119:647-51.

27. Gilden DH. Clinical practice. Bell's Palsy. N Engl J Med. 2004; 351(13):1323-31.

28. Alberton DL, Zed PJ. Bell's palsy: A review of treatment using antiviral agents. Ann Pharmacother 2006; 40(10):1838-42. 